\title{
Sistem Informasi UKKO untuk Peningkatan Kinerja Pegawai Studi Kasus PT.PLN (Persero) Tangerang
}

\author{
Giandari Maulani*1 $^{1}$, Mila Tryutami Karina ${ }^{2}$, Indra Setiawan ${ }^{3}$ \\ ${ }^{1,2}$ Program Studi Sistem Informasi STMIK Raharja, ${ }^{3}$ Program Studi Teknik Informatika \\ STMIK Raharja \\ Email: *1iandari@ raharja.info, ${ }^{2}$ mila.tryutami@ raharja.info, ${ }^{3}$ indra@ raharja.info
}

\begin{abstract}
Abstrak
PT.PLN (Persero) merupakan Badan Usaha Milik Negara yang berfokus dibidang penyediaan kelistrikan untuk masyarakat di Indonesia. UKKO singkatan dari Unit Kegiatan Kerja Operasional yang ada didalam PT.PLN (Persero). Penerapan sistem UKKO dalam perusahaan dibutuhkan untuk mendukung kegiatan pengarsipan menjadi lebih baik serta mampu meningkatkan kinerja para pegawainya. Studi kasus penelitian ini pada PT.PLN (Persero) khususnya di PT.PLN (Persero) Basecamp Cikupa Tangerang. Permasalahan timbul karena masih digunakannya sistem manual yang berakibat memperlambat kinerja pegawai. Untuk penyelesaiannya, maka PT.PLN (Persero) Tangerang membutuhkan suatu sistem informasi UKKO berbasis website sebagai upaya peningkatan kinerja pegawai. Tujuan penelitian ini yakni pembuatan sistem informasi UKKO yang dapat dijadikan sumber informasi lengkap, dapat mengurangi kesalahan penginputan dan lebih hemat waktu. Metodologi penelitian ini berupa metode pengumpulan data seperti observasi, wawancara, studi pustaka, metode perancangan dan metode pengujian Black Box Testing. Hasil akhir penelitian ini berbentuk Aplikasi Sistem Informasi UKKO berbasis Website untuk peningkatan kinerja pegawai PT.PLN (Persero) Tangerang.
\end{abstract}

Kata Kunci-Sistem Informasi UKKO, Kinerja Pegawai.

\begin{abstract}
PT. PLN (Persero) is a State-owned enterprise that focuses in the field of the provision of electricity to the community in Indonesia. UKKO stands for operational Work Unit is in PT. PLN (Persero). The application of the system of UKKO within the company are required to support the activities of archiving for the better as well as being able to improve the performance of its officers. Case study research at PT. PLN (Persero) PT. PLN (Persero) Basecamp Cikupa Tangerang. The problems arise because it is still used manual systems which result in slowing down the performance of the employees. To complete, then the PT. PLN (Persero) Tangerang need a website-based information system of UKKO in an effort to increase the performance of employees. The purpose of this research i.e. information systems making the source of UKKO complete information, can reduce penginputan error and more time-saving. Methodology this research in the form of data collection methods such as observation, interviews, literature studies, methods of design and testing method of Black Box Testing. The end result of this research information systems Applications-shaped UKKO-based Website for performance improvement clerk PT. PLN (Persero) Tangerang.
\end{abstract}

Keywords-UKKO information systems, Employee Performance. 


\section{PENDAHULUAN}

Pemanfaatan energi listrik digunakan untuk berbagai kebutuhan seperti kebutuhan rumah tangga, komersial, instansi pemerintahan, industri-industri serta usaha lainnya. Kebutuhan energi listrik mengalami peningkatan setiap tahunnya, dengan semakin meningkatnya kebutuhan ini, PT.PLN (Persero) sebagai Badan Usaha Milik Negara dituntut agar dapat mencukupi segala kebutuhan listrik untuk masyarakat dengan mutu yang baik, serta untuk menyalurkan energi listrik ke berbagai cabang yang tersebar meluas disetiap wilayah Indonesia dengan baik dan merata. Studi kasus penelitian ini yakni kepada PT.PLN (Persero) Tangerang, khususnya di PT.PLN (Persero) Basecamp Cikupa yang beralamat di Jalan Raya Serang, KM.17, Cikupa Tangerang, yang pada kala itu masih digunakannya sistem manual ,yakni masih melakukan kegiatan catat mencatat untuk mengetahui uraian kegiatan yang terdapat didalam Unit Kegiatan Kerja Operasional (UKKO). PT.PLN (Persero) Tangerang membutuhkan suatu sistem informasi UKKO berbasis Website yang dapat memberikan berbagai informasi secara lengkap, akurat, terperinci dan dapat meminimalisir terjadinya kesalahan penginputan sekaligus agar kinerja para pegawainya dapat terus meningkat. Dengan dibuatnya sistem informasi yang terkomputerisasi ini diharapkan kegiatan pengarsipan didalam UKKO dapat terjaga dengan baik, rapi dan terstruktur, yang berimbas kepada penghematan waktu kerja pegawai, yang tentunya berdampak positif untuk meningkatkan kinerja para pegawai di PT.PLN (Persero) Tangerang tersebut.

\section{METODE PENELITIAN}

Dalam melaksanakan penelitian ini digunakan beberapa metodologi penelitian, yaitu sebagai berikut : 1) Metode Pengumpulan Data yang terdiri dari: a) Observasi (Observation); Observasi dilakukan secara langsung dengan mendatangi PT.PLN (Persero) khususnya pada PT. PLN (Persero) Basecamp Cikupa yang berdomisili di Jl. Raya Cikupa Pasar Kemis, Desa Pasir Gadung, Kecamatan Cikupa, Kabupaten Tangerang, untuk mengumpulkan data-data dengan cara pengamatan langsung terhadap kegiatan-kegiatan yang sedang berjalan saat itu untuk mengetahui permasalahan apasaja yang terjadi didalam sistemnya. b) Wawancara (Interview); Pada metode ini, dilakukanlah tanya jawab secara langsung dengan Stakeholder Bpk. Edi Sastra dengan jabatan sebagai Asisten Manajer yang mana pekerjaannya berkaitan dengan sistem UKKO saat itu, guna mendapatkan informasi yang jelas dan akurat langsung dari sumbernya. c) Studi Pustaka (Literatur Review); Untuk Studi Pustaka penelitian ini bersumber dari Literatur Review yang berkaitan, dari berbagai buku dan jurnal yang ada hubungannya dengan penelitian ini sebagai bahan referensi. 2) Metode Perancangan digambarkan dengan diagram-diagram UML (Unified Modelling Language), untuk rancangan sistem yang akan dibuat. Pembuatan database beserta programnya disesuaikan berdasarkan kebutuhan-kebutuhan Stakeholder yang sesuai dengan elisitasi. Untuk bahasa pemogramannya menggunakan PHP (Hypertext Preprocessor). 3) Metode Pengujian (Testing); digunakan metode pengujian yang bernama Black Box Testing untuk menunjukkan fungsi-fungsi yang ada di dalam sebuah perangkat lunak. Sebagai contoh apakah pemasukan data/arsipnya diterima dengan benar, kemudian keluaran data/arsip yang dihasilkannya sesuai tujuan PT.PLN (Persero) Tangerang. Setelah dilakukan analisa, maka terdapat beberapa permasalahan yang terangkum kedalam rumusan masalah, antara lain : 1) Apakah sistem UKKO pada PT.PLN (Persero) Tangerang sudah berjalan dengan baik? 2) Apakah kinerja para pegawai PT.PLN (Persero) Tangerang mengalami peningkatan? 3) Apakah sistem UKKO dapat membantu PT.PLN (Persero) Tangerang dalam mempermudah pekerjaan? Pertanyaan-pertanyaan diatas muncul karena yang menjadi permasalahan selama ini yakni mengenai penanganan pengarsipan yang masih manual dan belum dapat menghemat waktu kerja sehingga memperlambat kinerja kerja pegawai secara keseluruhan. Penelitian ini memiliki landasan teori yang berisi tentang definisi seperti dibawah ini :

Definisi Sistem 
Menurut pendapat Marshall Romney dan JP.Steinbart; Sistem adalah "Suatu rangkaian yang terdiri dari 2 (dua) atau lebih komponen yang berhubungan dan saling berinteraksi satu sama lain untuk mencapai tujuan dimana sistem biasanya terbagi dalam sub-sub sistem yang kecil mendukung sistem yang lebih besar. ${ }^{[1]}$

Definisi Informasi

Menurut Sri Mulyani; Informasi adalah Data-data yang telah diolah, ditujukan untuk seseorang, organisasi, atau siapa saja yang membutuhkannya. ${ }^{[2]}$

Definisi Kinerja

Menurut Erjati Abas; Kinerja adalah Ungkapan kemampuan yang didasari oleh pengetahuan, sikap, motivasi dan keterampilan dalam menghasilkan sesuatu. ${ }^{[3]}$

Definisi Website

Menurut Untung Rahardja,dkk ; Website adalah keseluruhan halaman Website yang terdapat didalam sebuah domain yang mengandung informasi. ${ }^{[4]}$

Definisi pengujian Black Box Testing

Menurut Ika Yuniva dan Dany Hestiyanto; Black Box Testing/pengujian kotak hitam adalah menguji perangkat lunak dari sisi spesifikasi fungsionalnya saja, tidak menguji desain dan kode programnya. ${ }^{[5]}$

Definisi UML

Menurut Indragriha taufik dan George Pri; Unified Modeling Language (UML) merupakan Keluarga notasi-notasi grafis yang didukung dengan meta model tunggal yang dapat membantu pendeskripsian desain sistem software, khusus sistem yang dibangun dengan menggunakan pemrograman yang berorientasi objek. ${ }^{[6]}$

Literature Review

Manfaat Literature review menurut Khanna Tiara,dkk yakni untuk identifikasi kesenjangan, menghindari pembuatan ulang, identifikasi metode-metode yang pernah dilakukan dan meneruskan penelitian sebelumnya. ${ }^{[7]}$ Beberapa Literature Review dalam penelitian ini, antara lain :

1. Penelitian Apriyansyah Putra [2015] Universitas Sriwijaya (UNSRI) dalam Jurnal Generic Vol.10 No.1 yang berjudul : "Sistem Pengarsipan EDM/Elektronik Dokumen Mutu Universitas Sriwijaya". Penelitian ini membahas pengarsipan secara elektronik dalam sebuah organisasi diperlukan untuk mensupport kegiatan pengarsipan dalam upaya tercapainya efektifitas serta efisiensi dalam pengelolaan serta mampu melestarikan arsip yang memilik informasi atau nilai penting bagi penggunanya. ${ }^{[8]}$

2. Penelitian Sandy Kosasi [2016] STMIK Pontianak dalam Jurnal Teknologi Informasi Vol.15 No.4 yang berjudul "Pengukuran Kinerja Sistem Informasi Karyawan Menggunakan Balanced Scorecard'. Penelitian ini membahas kualitas dan keamanan sistem informasi membutuhkan pemeliharaan lebih lanjut. Kualitas dalam menyediakan informasi karyawan masih memiliki keterbatasan dengan sejumlah kendala dalam mengorganisasikan kepemilikan sistem secara tepat. Tujuan peneliti untuk dapat mengetahui kontribusi dan pemanfaatan melalui investasi aplikasi TI dalam menunjang kebututuhan sistem informasi karyawan. Penelitian ini melakukan survey dengan penggunaan metode Deskriptif Analitis. ${ }^{[9]}$

3. Penelitian Mohammed Inuwa [2015] yang berjudul : "The Impact of Job Statisfaction, Job Attitude and Equity on Employee Performance". Tujuan Penelitiannya untuk menciptakan sebuah kerangka kerja konseptual yang berfungsi sebagai dasar untuk memahami bagaimana kepuasan kerja, sikap kerja dan ekuitas yang dapat mempengaruhi kinerja karyawan ditempat kerja. ${ }^{[10]}$

4. Penelitian Muhammad Rizal, dkk [2014] yang berjudul : "Effect of Compensation on Motivation, Organizational Commitment \& Employee Performance (Studies At Local Revenue Management In Kendari City)”. Penelitian ini bertujuan untuk menguji secara empiris efek kompensasi pada motivasi, komitmen organisasi kinerja karyawan. Studi ini menemukan bahwa kompensasi tidak dapat secara langsung meningkatkan kinerja 
karyawan, tetapi mampu meningkatkan motivasi dan memperkuat komitmen organisasi.

Perbedaan Literature review diatas dengan penelitian ini yaitu : 1) Penelitian ini menghasilkan sistem informasi UKKO yang lebih baik bagi perusahaan dalam hal ini PT.PLN (Persero) Tangerang karena berbasis Website sehingga pekerjaan dapat dilakukan lebih cepat dan optimal. 2) Penelitian ini mempermudah para pegawai dalam membuat laporan rutin UKKO. 3) Penelitian ini menghasilkan arsip UKKO yang update dan hemat waktu sehingga dapat meningkatkan kinerja pegawai PT.PLN (Persero) Tangerang.

\section{HASIL DAN PEMBAHASAN}

\subsection{Rancangan Sistem}

Rancangan sistem informasi UKKO untuk peningkatan kinerja pegawai pada PT.PLN (Persero) Tangerang digambarkan menggunakan diagram Unified Modeling Language (UML) yang merupakan bahasa permodelan untuk software yang berorientasi objek, seperti dibawah ini:

\subsubsection{Diagram Usecase}

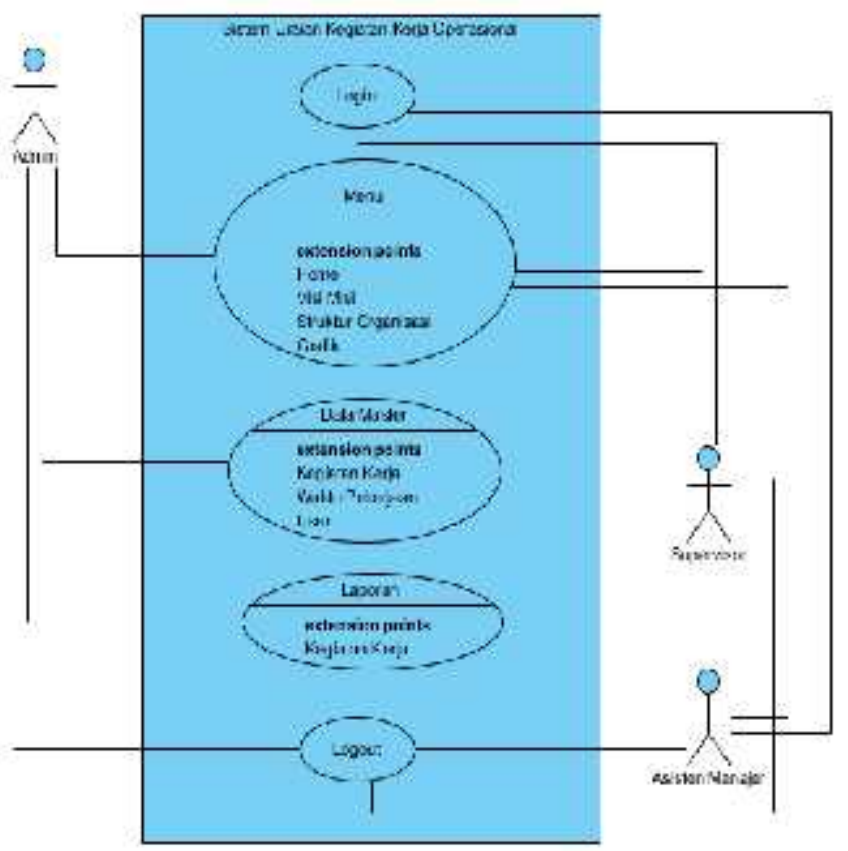

Gambar 1. Use case diagram sistem

Berdasarkan gambar 1. Use case diagram sistem, terdapat: 1 Sistem yang mencakup seluruh kegiatan UKKO pada PT.PLN (Persero) Tangerang, 2 actor yang melakukan kegiatan, diantaranya : Supervisor, Asisten Manajer dan Admin, didalam Usecase diagram tersebut terdapat : 1 include Login, 3 Extend Use Case : Menu, Data Master, Laporan dan 1 include Logout. 


\subsubsection{Diagram Sequence}

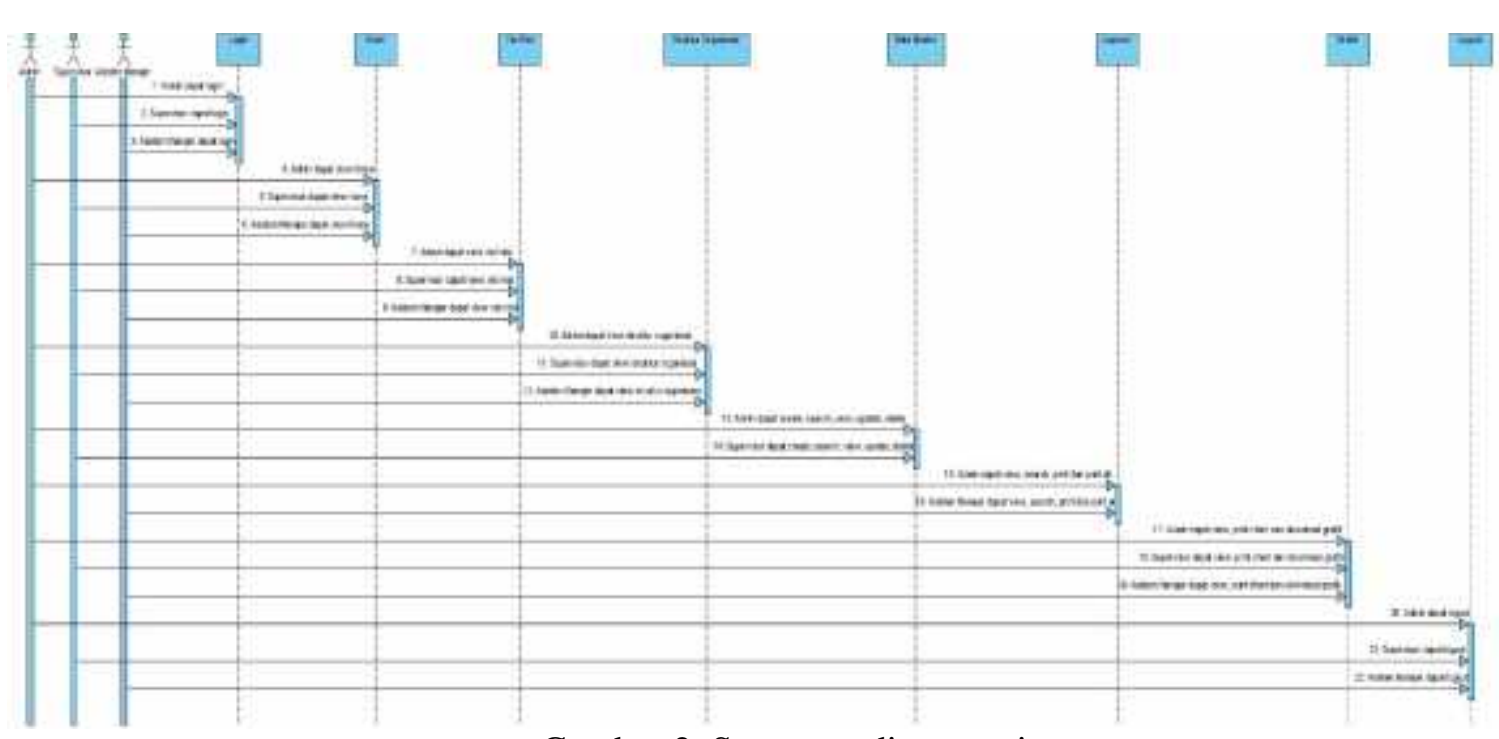

Gambar 2. Sequence diagram sistem

Pada gambar 2. Sequence diagram sistem terdapat: 3 actor yang melakukan kegiatan, yaitu Admin, Supervisor dan Asisten Manajer , 8 lifeline yang saling berinteraksi, yaitu Login, Home, Visi Misi, Struktur Organisasi, Data Master, Laporan, Grafik dan Logout, 22 Message yang memuat informasi-informasi tentang suatu kegiatan atau aktivitas yang terjadi yang dilakukan oleh actor.

\section{Uji Validitas}

Metode pengujian/Uji Validitas pada penelitian ini menggunakan Blackbox Testing. Blackbox Testing merupakan metode pengujian perangkat lunak yang memfokuskan kepada keperluan software, oleh karena itu metode Blackbox Testing ini dapat mengetahui dan memastikan apakah pemasukan data diterima dengan benar dan keluaran data yang dihasilkan sesuai dengan yang diharapkan.

Tabel 1. Blackbox Testing pada Menu Login

\begin{tabular}{|c|c|c|c|c|c|}
\hline No. & $\begin{array}{c}\text { Skenario } \\
\text { Pengujian }\end{array}$ & Test Case & $\begin{array}{l}\text { Hasil yang } \\
\text { diharapkan }\end{array}$ & Hasil Pengujian & Ket. \\
\hline 1. & $\begin{array}{l}\text { Mengisikan } \\
\text { dengan salah satu } \\
\text { data benar dan } \\
\text { satu lagi salah, } \\
\text { lalu langsung } \\
\text { klik login. }\end{array}$ & $\frac{}{2-}$ & $\begin{array}{l}\text { Sistem akan } \\
\text { menolak akses } \\
\text { login dan } \\
\text { menampilkan } \\
\text { pesan "incorrect } \\
\text { username or } \\
\text { password" }\end{array}$ & 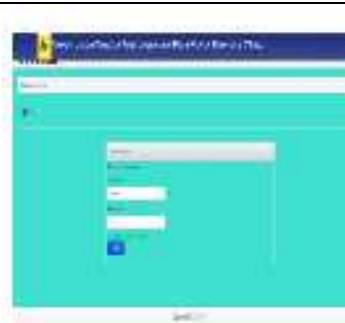 & Valid \\
\hline 2. & $\begin{array}{l}\text { Mengisikan } \\
\text { username dan } \\
\text { password dengan } \\
\text { benar, lalu klik } \\
\text { login. }\end{array}$ & 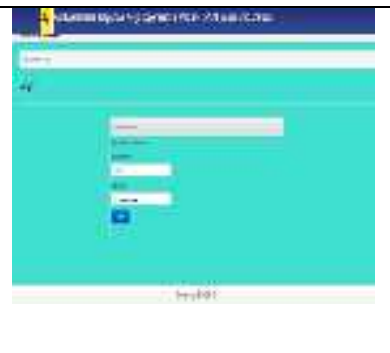 & $\begin{array}{l}\text { Sistem akan } \\
\text { melakukan cek } \\
\text { kesesuain } \\
\text { username dan } \\
\text { password, } \\
\text { apabila benar } \\
\text { maka sistem } \\
\text { akan masuk. }\end{array}$ & 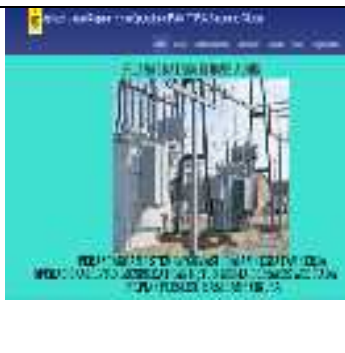 & Valid \\
\hline
\end{tabular}


Tabel 2. Black Box Testing Input Data Petugas

\begin{tabular}{|c|c|c|c|c|c|}
\hline No. & $\begin{array}{c}\text { Skenario } \\
\text { Pengujian }\end{array}$ & Test Case & $\begin{array}{l}\text { Hasil yang } \\
\text { diharapkan }\end{array}$ & Hasil Pengujian & Ket. \\
\hline 1. & $\begin{array}{l}\text { Klik menu data } \\
\text { master dan klik } \\
\text { menu kegiatan } \\
\text { kerja lalu create } \\
\text { untuk mengisi } \\
\text { data kegiatan } \\
\text { kerja. }\end{array}$ & E & $\begin{array}{l}\text { Sistem akan } \\
\text { menampilkan } \\
\text { halaman data } \\
\text { kegiatan kerja. }\end{array}$ & 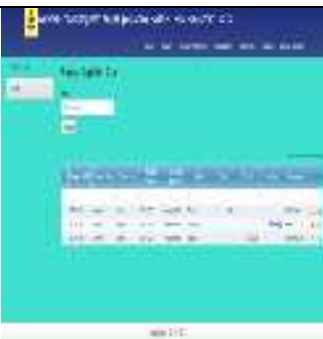 & Valid \\
\hline 2. & $\begin{array}{l}\text { Klik update pada } \\
\text { menu kegiatan } \\
\text { kerja untuk } \\
\text { menambah atau } \\
\text { mengubah data } \\
\text { kegiatan kerja. }\end{array}$ & 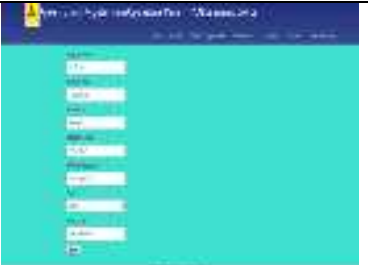 & $\begin{array}{l}\text { Sistem akan } \\
\text { menampilkan } \\
\text { halaman data } \\
\text { kegiatan kerja. }\end{array}$ & 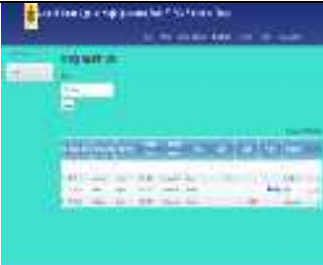 & Valid \\
\hline
\end{tabular}

Tabel 3. Black Box Testing Input Data Customer

\begin{tabular}{|l|l|l|l|l|l|}
\hline No. & \multicolumn{1}{|c|}{$\begin{array}{c}\text { Skenario } \\
\text { Pengujian }\end{array}$} & \multicolumn{1}{|c|}{ Test Case } & \multicolumn{1}{c|}{$\begin{array}{l}\text { Hasil yang } \\
\text { diharapkan }\end{array}$} & Hasil Pengujian & Ket. \\
\hline 1. & $\begin{array}{l}\text { Klik menu data } \\
\text { master } \text { dan klik } \\
\text { menu waktu } \\
\text { pekerjaan lalu } \\
\text { create untuk } \\
\text { mengisi data } \\
\text { jadwal kegiatan } \\
\text { kerja untuk } \\
\text { waktu } \\
\text { kedepannya. }\end{array}$ & $\begin{array}{l}\text { Sistem akan } \\
\text { menampilkan } \\
\text { halaman data waktu } \\
\text { pekerjaan. } \\
\text { menu waktu } \\
\text { pekerjaan untuk } \\
\text { mengubah data } \\
\text { waktu pekerjaan. }\end{array}$ & $\begin{array}{l}\text { Sistem akan } \\
\text { menampilkan } \\
\text { halaman data waktu } \\
\text { pekerjaan. }\end{array}$ & & Valid \\
\hline 2. & & & & \\
\hline
\end{tabular}

Tabel 4. Black Box Testing Data Wilayah

\begin{tabular}{|l|l|c|c|c|c|}
\hline No. & \multicolumn{1}{|c|}{$\begin{array}{c}\text { Skenario } \\
\text { Pengujian }\end{array}$} & \multicolumn{1}{|c|}{ Test Case } & \multicolumn{1}{c|}{$\begin{array}{l}\text { Hasil yang } \\
\text { diharapkan }\end{array}$} & Hasil Pengujian & Ket. \\
\hline 1. & $\begin{array}{l}\text { Klik menu data } \\
\text { master dan klik } \\
\text { menu } \text { user lalu } \\
\text { create user untuk } \\
\text { membuat } \text { user } \\
\text { baru. }\end{array}$ & $\begin{array}{l}\text { Sistem akan } \\
\text { menampilkan } \\
\text { halaman data } \text { user. }\end{array}$ & Valid & & \\
\hline
\end{tabular}




\begin{tabular}{|l|l|l|l|l|l|}
\hline 2. & $\begin{array}{l}\text { Klik update pada } \\
\text { menu user untuk } \\
\text { mengubah } \text { user. }\end{array}$ & $\begin{array}{l}\text { Sistem akan } \\
\text { menampilkan } \\
\text { halaman data user. }\end{array}$ & Valid \\
\hline
\end{tabular}

Dibawah ini merupakan hasil implementasi interface tampilan setiap menu dari Sistem Informasi UKKO untuk peningkatan kinerja pegawai PT.PLN (Persero) Tangerang yang berbasis Website :

1. Tampilan Menu Login

Tampilan menu login muncul jika telah masuk ke web browser. User harus memasukan username dan password terlebih dahulu. Sistem dapat digunakan oleh admin.

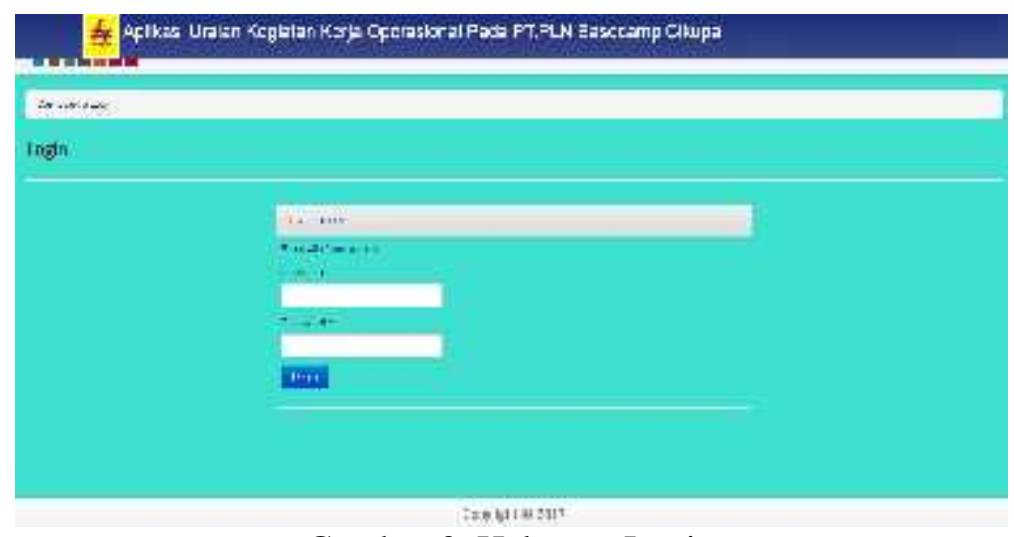

Gambar 3. Halaman Login

2. Tampilan Menu Home

Tampilan menu home muncul jika telah berhasil login. Menu home adalah tampilan awal sistem.

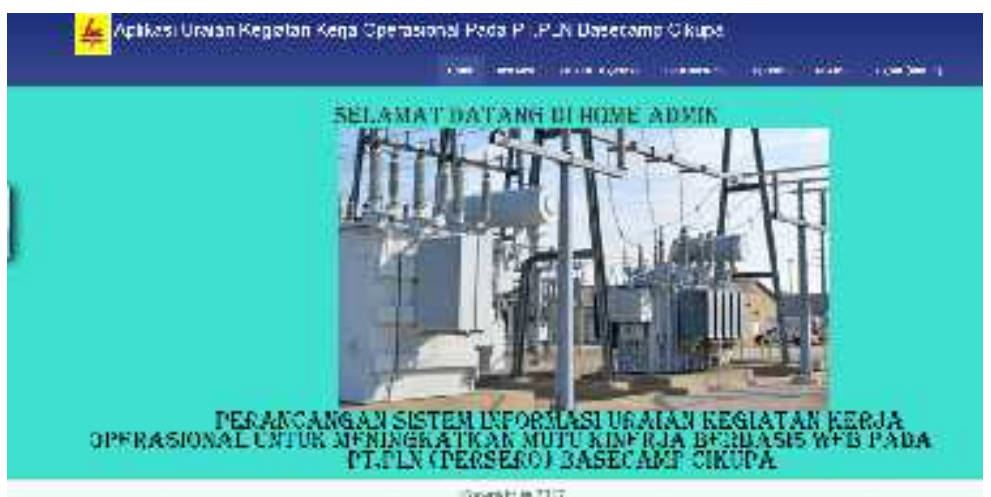

Gambar 4. Menu Utama (Dashboard)

3. Tampilan menu Visi Misi

Tampilan menu visi misi muncul jika telah berhasil login. Menu visi misi adalah visi misi yang terdapat di PT.PLN (Persero) Tangerang. 


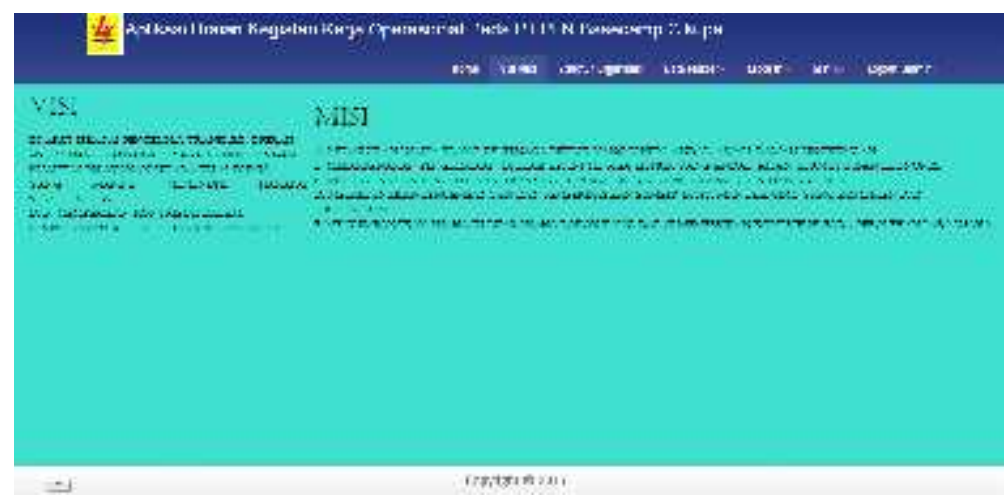

Gambar 5. Menu Master Data Petugas

4. Tampilan menu Struktur Organisasi

Tampilan menu struktur organisasi muncul jika telah berhasil login. Menu struktur organisasi adalah struktur organisasi yang terdapat di PT.PLN (Persero) Tangerang.

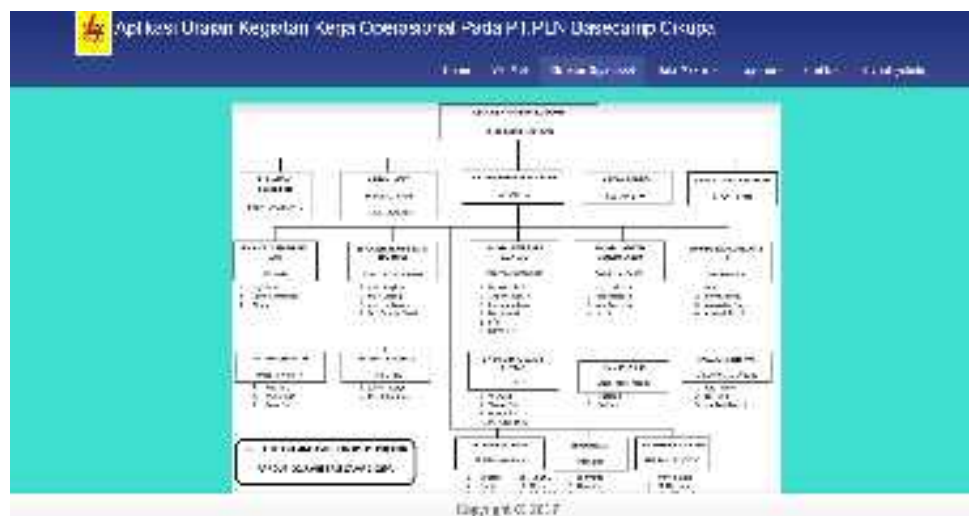

Gambar 6. Menu input master data petugas

5. Tampilan menu Kegiatan Kerja

Tampilan menu kegiatan kerja muncul jika telah berhasil login. Menu ini berfungsi untuk view, untuk update, delete dan search status.

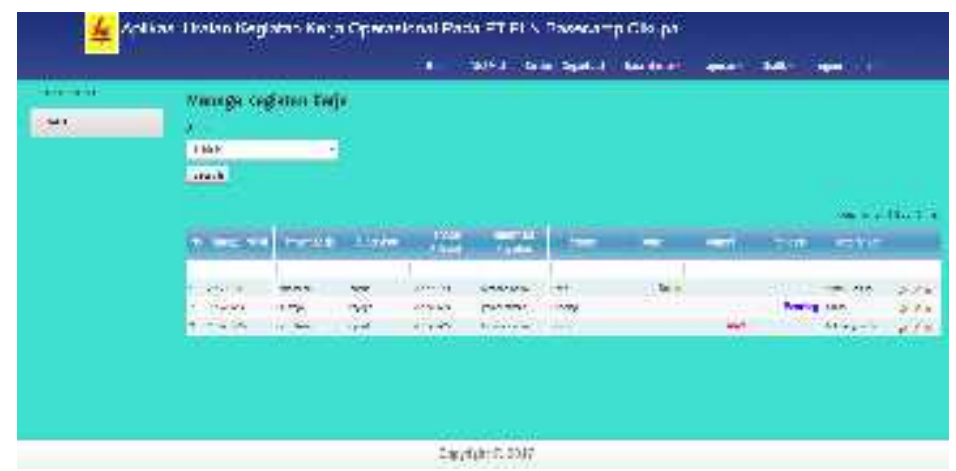

Gambar 7. Menu Master Data Customers

6. Tampilan menu Create Kegiatan Kerja

Tampilan menu create kegiatan kerja muncul jika telah berhasil login. Menu ini berfungsi untuk creat kegiatan kerja operasional. 


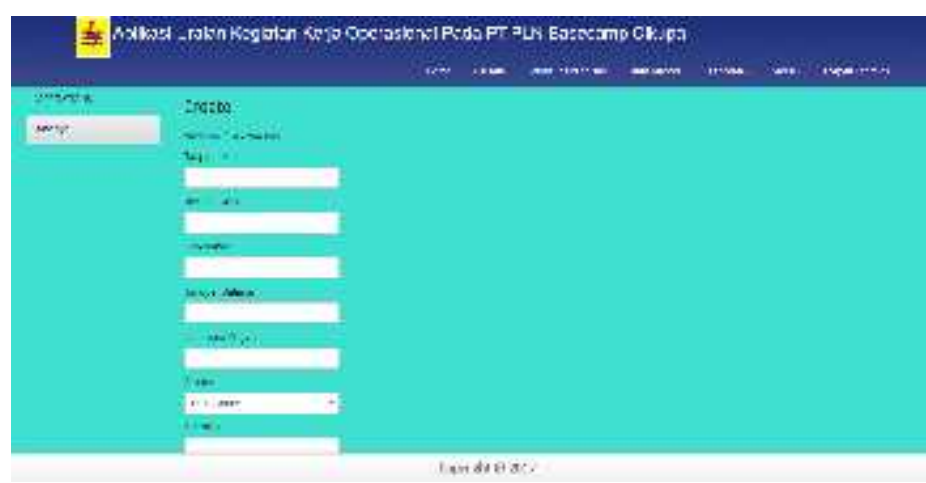

Gambar 8. Menu input master data customers

7. Tampilan menu Waktu Pekerjaan

Tampilan menu waktu pekerjaan muncul jika telah berhasil login. Menu ini berfungsi untuk view, update, delete, dan search tanggal mulai waktu pekerjaan.

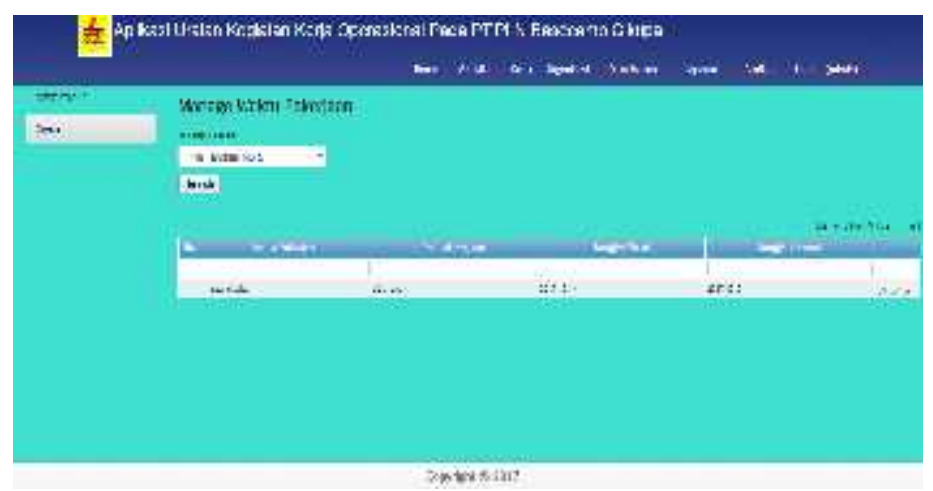

Gambar 9. Menu input master data wilayah

8. Tampilan menu Create Waktu Pekerjaan

Tampilan menu create waktu pekerjaan muncul jika telah berhasil login. Menu ini berfungsi untuk membuat jadwal waktu pekerjaan yang akan datang.

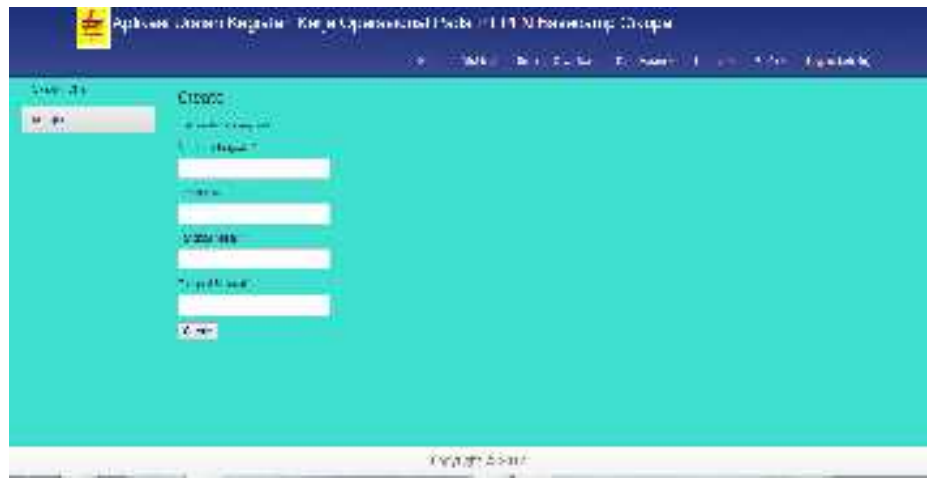

Gambar 10. Menu input master data wilayah

9. Tampilan menu Manage User

Tampilan menu user muncul jika telah berhasih login. Menu ini berfungsi untuk view, update, delete, dan search username. 


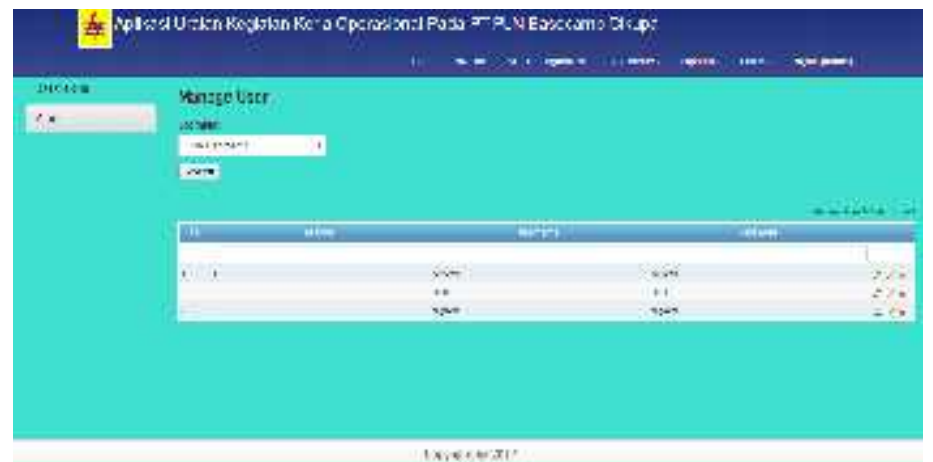

Gambar 11. Menu input master data cara bayar

10. Tampilan menu Create User

Tampilan menu create user muncul jika telah berhasil login. Menu ini berfungsi untuk membuat user baru dengan memasukan username baru dan password baru.

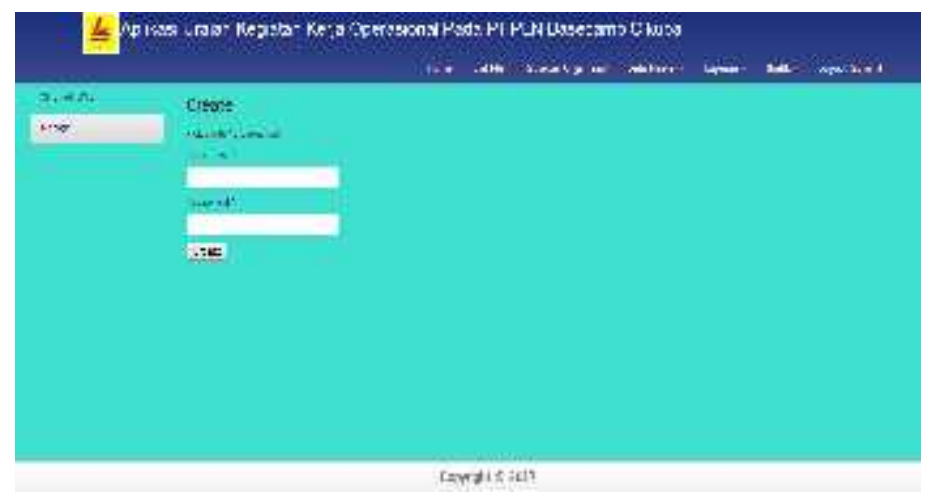

Gambar 12. Menu input master data cara bayar

11. Tampilan menu Laporan Kegiatan Kerja

Tampilan menu laporan kegiatan kerja muncul jika telah berhasil login. Menu ini laporan kegiatan kerja operasional dan bisa search status.

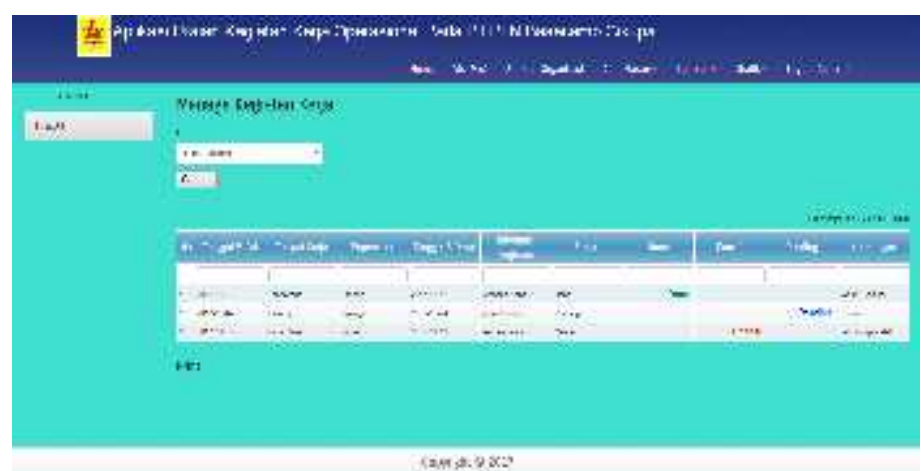

Gambar 13. Menu input data pembayaran

12. Tampilan menu Grafik

Tampilan menu grafik muncul jika telah berhasil login. Dalam menu ini dapat melihat grafik pekerjaan supervisor yang dapat mengerjakan pekerjaannya dengan cepat atau tidak : 


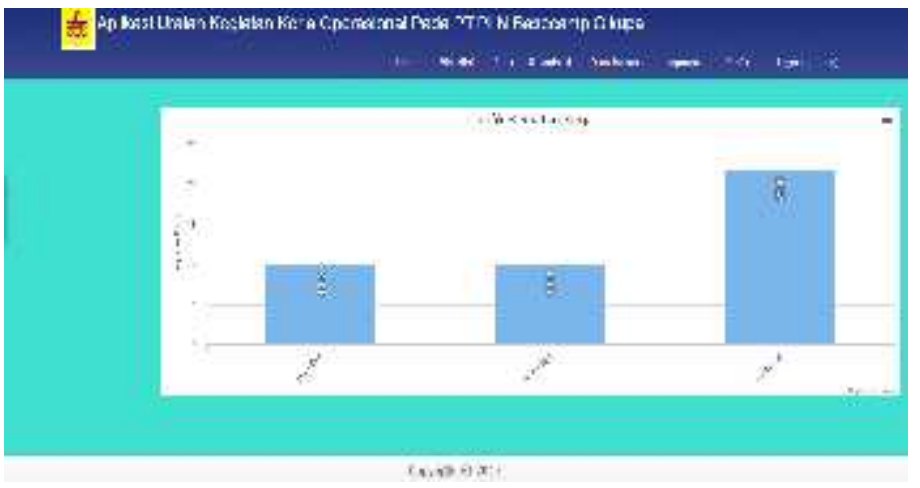

Gambar 14. Menu input data pembayaran

13. Tampilan Print Grafik

Tampilan menu print grafik muncul jika telah berhasil login. Menu ini berfungsi untuk mencetak grafik.

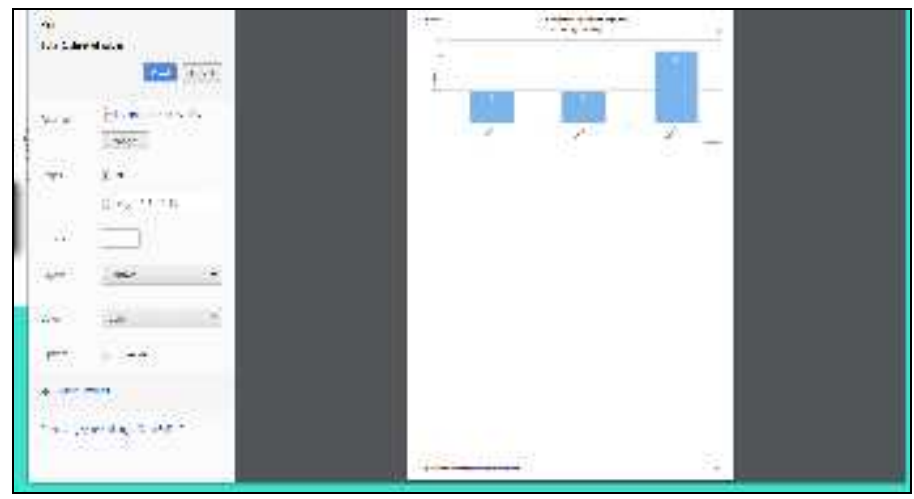

Gambar 15. Menu input data laporan bulanan

\section{KESIMPULAN}

Berdasarkan hasil penelitian yang telah dilakukan, maka diambil kesimpulan,yaitu: Sistem UKKO yang berjalan saat ini pada PT.PLN (Persero) Tangerang masih berjalan secara manual dengan cara mencatat, sehingga proses dalam pengerjaan tidak efektif dan efisien. Pada PT.PLN (Persero) Tangerang sistem UKKO yang berjalannya belum terhimpun di satu database yang terkomputerisasi. Sistem informasi UKKO dapat membantu PT.PLN (Persero) Tangerang dalam mempermudah kinerja pegawai dan PT.PLN (Persero) Tangerang membutuhkan sebuah sistem informasi berbasis website, untuk membuat sebuah sistem informasi berbasis website maka dibutuhkan program aplikasi PHP dan MySQL sebagai tempat penyimpanan data sehingga memudahkan pegawai dalam membuat laporan UKKO.

\section{SARAN}

Saran untuk pengembangan sistem informasi UKKO agar menjadi lebih baik, antara lain : Disarankan PT.PLN (Persero) Tangerang dapat menggunakan sistem informasi UKKO berbasis website agar semua yang di inginkan oleh perusahaan listrik ini dapat meminimalisir hal-hal yang selama ini jadi masalah. Untuk dapat memaksimalkan sistem informasi UKKO yang telah dibuat, maka perlu adanya pelatihan kepada admin dan pegawai terkait yang akan menggunakan sistem informasi tersebut agar lebih dimengerti dan dipahami serta sistem dapat meningkatkan kinerja pegawai dan dapat bermanfaat untuk perusahaan. Apabila sistem yang baru sudah berjalan dengan baik maka perlu diperhatikan, dirawat dan dilakukan evaluasi secara 
berkala terhadap sistem untuk selanjutnya diadakan perbaikan sesuai dengan perubahan dan perkembangan PT.PLN (Persero) Tangerang.

\section{UCAPAN TERIMA KASIH}

Terima Kasih kepada rekan-rekan sejawat STMIK Raharja yang telah mendukung dalam proses penerbitan artikel ini.

\section{DAFTAR PUSTAKA}

[1] Romney, Marshall B. Paul John Steinbert, 2015, "Acounting Information System, 13 ${ }^{\text {th }}$ ed". England: Person Education Limited.

[2] Mulyani, Sri. 2016, "Metode dan Analisis Perancangan Sistem". Bandung: Abdi Sistematika.

[3] Abas, Erjati. 2017, "Magnet Kepemimpinan Kepala Madrasah Terhadap Kinerja Guru". Jakarta: PT Elex Media Komputindo.

[4] Rahardja,Untung, Ray Indra Taufik Wijaya, Endah Nirmala Dewi, 2017, "Peningkatan Rank Alexa menggunakan metode SEO untuk meningkatkan web visitor pada official sute iLearning Plus". STMIK Raharja: Jurnal CCIT. Vol.10 No.1.

[5] Yuniva,Ika, Dany Hestiyanto, 2018, "Perancangan Web e-Commerce untuk penjualan sepatu dengan pendekatan model Classic Life Cycle". STMIK Raharja: Jurnal CERITA. Vol.4 No.1.

[6] Taufik,Indragriha, George Pri, 2017, "Perancangan aplikasi koperasi simpan pinjam berbasis web (studi kasus) Koperasi Mitra Setia)". Jurnal ilmiah ekonomi. Vol.5 Edisi.10.

[7] Tiara,Khanna, Mukti Budiarto, Olis rosmawati, 2017, "Optimalisasi MIBEW Messenger guna meningkatkan pelayanan iDuHelp! Online pada Perguruan Tinggi". STMIK Raharja: Jurnal ICIT. Vol.3 No.1.

[8] Putra, Apriansyah. 2015, "Sistem Pengarsipan Elektronik Dokumen Mutu Universitas Sriwijaya". Universitas Sriwijaya: Jurnal Generic. Vol.10. No-1.

[9] Kosasi, Sandy. 2016, "Pengukuran Kinerja Sistem Informasi Karyawan Menggunakan IT Balanced Scorecard'. STMIK Pontianak: Jurnal Techno.com. Vol.15 No-4.

[10] Inuwa, Muhamed. 2015, "The Impact of Job Statisfaction, Job Attitude And Equity On Employee Performance”. Bauchi State University, Gadau, Nigeria: The International Journal of Business and Management. Vol.3 Issue 5.

[11] Rizal, Muhamad. Muhammad Rizal, M.Syafi'ie Idrus, Djumahir, Rahayu Mintarti, 2014, "Effect of Compensation On Motivation, Organizational Commitment and Employee Performance (Studies At Local Reveneu Management In Kendari City)". Brawijaya University: Jurnal International Journal of Business and Management Invention.Vol.3_issue2. 